\title{
ACUTE DERMATOMYOSITIS PRESENTING WITH PULMONARY MANIFESTATIONS
}

\author{
BY \\ LILLY M. S. DUBOWITZ and VICTOR DUBOWITZ \\ From the Children's Hospital, Sheffield, and the Department of Child Health, \\ University of Sheffield
}

(RECEIVED FOR PUBLICATION SEPTEMBER 16, 1963)

Dermatomyositis has been defined as an acute, subacute or chronic disease of unknown aetiology, characterized by oedema, dermatitis and a nonsuppurative inflammation of striated muscle. Since the original description by Wagner (1863) several hundred cases have been described. Many of these have occurred in children. Various drug therapies have been tried, with little success, and the place of steroid therapy is still debatable.

The following case is reported because of (a) an unusual mode of presentation, (b) the role of drugs as a possible precipitating factor, and (c) the favourable response to steroids as well as some of the dangers of steroid therapy.

\section{Case History}

Stephen C., aged 5 years, was admitted to the Sheffield Children's Hospital, acutely ill, on September 15, 1962, with a diagnosis of miliary tuberculosis.

Six weeks previously, following the detection of pulmonary tuberculosis in an uncle, a tuberculin test (Heaf) on Stephen was positive, and the radiograph showed an enlarged hilar gland. A week later he was started on isoniazid (INAH) and para-amino salicylic acid (PAS) at the Chest Clinic. He remained well until September 5 when he became 'off colour' and complained of headache, and three days later vomited. His practitioner diagnosed an upper respiratory tract infection and prescribed a sulphonamide. Later the same day he developed a rash that resembled measles: this was thought to be due to drug sensitivity, and on September 9 the PAS, INAH and sulphonamide were discontinued, and tetracycline was prescribed. Two days later he developed an urticaria-like rash, followed by swelling and a violet discoloration of the face, eyelids, hands and feet; much of the swelling subsided within 24 hours but the discoloration persisted. His general condition remained unchanged till 48 hours before admission (September 13) when he became drowsy and appeared generally worse.

At the time of admission (September 15) he was an acutely ill child, toxic looking and rather flushed. His temperature was $100 \cdot 4^{\circ} \mathrm{F}$. $\left(38^{\circ} \mathrm{C}.\right)$, pulse rate
140 a minute, respiratory rate 80 a minute, and the blood pressure was $105 / 60 \mathrm{~mm}$. Hg. A blotchy rash was present on the face and arms, violet on the face, more salmon coloured on the extremities. No swelling was noted. There was a mild generalized lymphadenopathy. The respirations were shallow, the breath sounds vesicular, and râles were present at both bases. The heart was clinically not enlarged. A soft systolic murmur was present at the apex. There was no guarding, tenderness or distension of the abdomen. The spleen was palpable one finger breadth below the costal margin. The liver was not palpably enlarged. There were no signs of meningism. The fundi were normal, and no miliary tubercles could be seen. There was generalized hypotonia and the tendon reflexes were sluggish but symmetrical. The plantar response was flexor. Investigations showed: White blood cells $13,200 /$ c.mm. with polymorphs $72 \%$, lymphocytes $24 \%$, monocytes $3 \%$ and eosinophils $1 \%$; erythrocytes $4,300,000$; erythrocyte sedimentation rate $19 \mathrm{~mm}$./hour (Westergren). The blood electrolytes were normal. The cerebrospinal fluid was normal. Chest radiograph showed miliary shadowing (Fig. 1).

Although a drug-sensitivity reaction was a likely diagnosis, the evidence in favour of miliary tuberculosis was so strong that it was decided to treat him along these lines. Streptomycin, PAS and INAH were accordingly again prescribed.

Twelve hours after admission he was worse, and there was a significant increase in vomiting. The signs in the chest were unchanged, but the heart rate had risen to 180 a minute. The deterioration was thought to be due to sensitivity to PAS, and this drug was therefore stopped. INAH and streptomycin were continued and steroids were added to the régime.

Over the next 24 hours his condition improved slightly, but on September 17 it was more or less the same as at the time of admission. The rash was unchanged. Coarse crepitations were still present at the lung bases. The heart was not enlarged, but he had tachycardia, triple rhythm and a systolic murmur. He had ptosis and significant generalized hypotonia and weakness. The latter was ascribed to the general debility.

At this stage the diagnosis was once again questioned. In view of the onset of symptoms and deterioration 


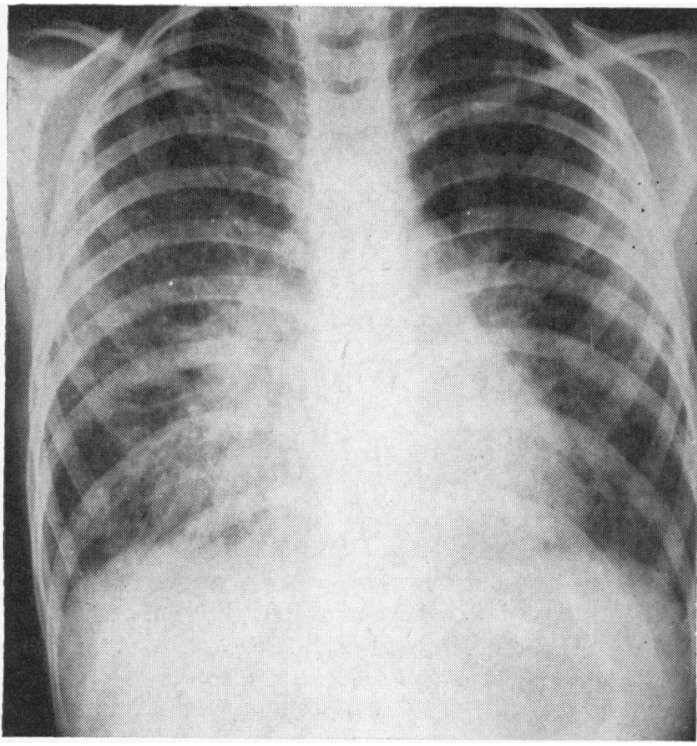

FIG. 1.-Chest radiograph on admission (September 15, 1962), showing miliary shadowing.

during five weeks of antituberculous therapy, and the continued absence of choroidal tubercles, it seemed unlikely that this illness was due to miliary tuberculosis. A very severe drug reaction was thought to be the better explanation. On these grounds the antituberculous medication was stopped but the cortisone was continued.

In the next 24 hours there was an improvement. The child was much more alert. He started to speak, though his voice was weak and tired easily. However, in spite of the general improvement, the ptosis and general weakness persisted and now seemed out of proportion to his illness. The tendon jerks were absent. The pulse and respiratory rate were still increased. There was considerable upper abdominal distension. A diagnosis of acute dermatomyositis was now suggested on the basis of the weakness, the rash, the cardiac involvement and the abdominal distension.

With this diagnosis in mind the mother was once again interrogated and the following history emerged.

The parents thought that he was completely normal, in comparison with his elder sister, till the age of $3 \frac{1}{2}$ years, when he was noted to be unsteady on his feet. He started to complain that his legs got tired and his parents often had to take him out in a push-chair. The symptoms appeared more severe when he started school at $4 \frac{1}{2}$ years, and this was ascribed to school phobia. Four months before his present illness, he had a rash resembling scarlet fever. No deterioration of muscle power was noted at the time. Six weeks before admission, at about the time the primary tuberculous focus was diagnosed, he complained of tiredness. This improved dramatically after he was started on PAS and INAH.

This history suggested that the muscle weakness was of long standing with a recent exacerbation. The

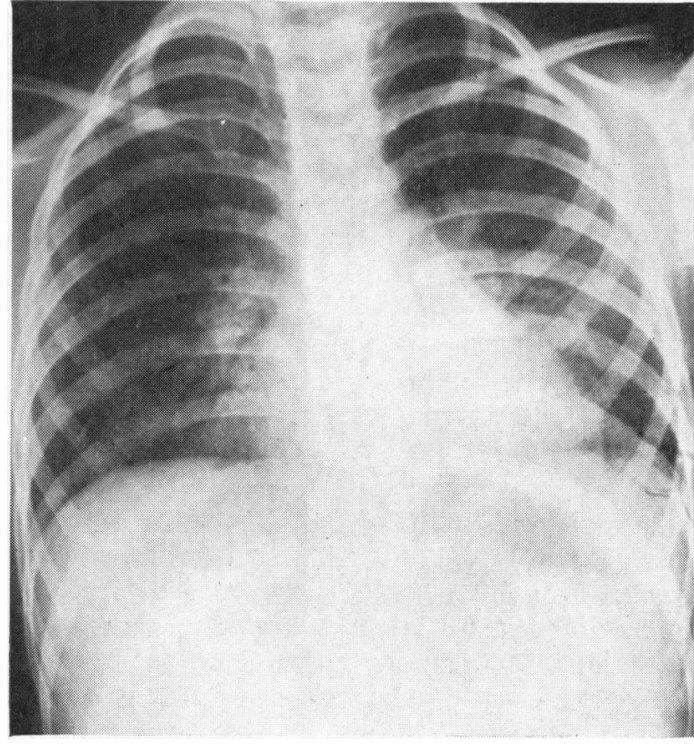

FIG. 2.-Chest radiograph (September 21, 1962), showing clear lung fields.

diagnosis of dermatomyositis was supported by the detailed muscle charting which showed generalized weakness (M.R.C. Grade 2 to 3), with the proximal muscles more severely affected than the distal; and by the raised serum enzyme levels, the transaminases being 195 units (S.G.O.T.) and 136 units (S.G.P.T.) and the creatine phosphokinase 11.7 units (normal: $<4$ units). Muscle biopsy of the quadriceps showed an overall normal architecture of muscle bundles, with fibre diameter ranging from 20-40 $\mu$. There were focal areas of muscle degeneration with increased sacrolemmal nuclei and fibroblast activity. There were also a number of foci of round cell infiltrations in relation to muscle fibres or perimysial blood vessels. There was no excess of connective tissue. The picture, although not florid, was thought to be in keeping with a polymyositis. The electrocardiogram showed inversion of $T$ wave from chest leads VI to V5. Electromyography was not done. There was no myoglobinuria.

By September 24 the rash had completely faded and a day later the muscle power had improved to the extent that he was able to walk a few steps. The tendon reflexes could be elicited. The ptosis and facial weakness were still present and the trunk muscles remained weak. The chest was clinically clear and a chest radiograph showed complete resolution (Fig. 2). The heart was clinically normal.

His condition continued to improve. By September 30 his muscle power was normal except for the trunk flexors. He was having prednisolone $30 \mathrm{mg}$./day. He then developed a vesicular eruption and two days later he became pyrexial and covered in blisters without surrounding erythema (Fig. 3). This eruption was thought to be due to an acute viral infection, either 
chicken-pox or herpes simplex, modified by steroid therapy. There had recently been cases of chicken-pox on the ward. He was treated with gamma globulin and daily injections of 40 units of A.C.T.H. in addition to his prednisolone. In the course of the next few days his condition deteriorated considerably; many of the vesicles became secondarily infected and he became very toxaemic. However, after a stormy course, the eruption subsided completely, leaving numerous scars, particularly on the face. The dosage of prednisolone was gradually reduced to a maintenance of $5 \mathrm{mg}$. daily and A.C.T.H. to 20 units weekly. He was discharged on September 28. At this stage he was clinically well, and apart from some residual weakness in the flexors

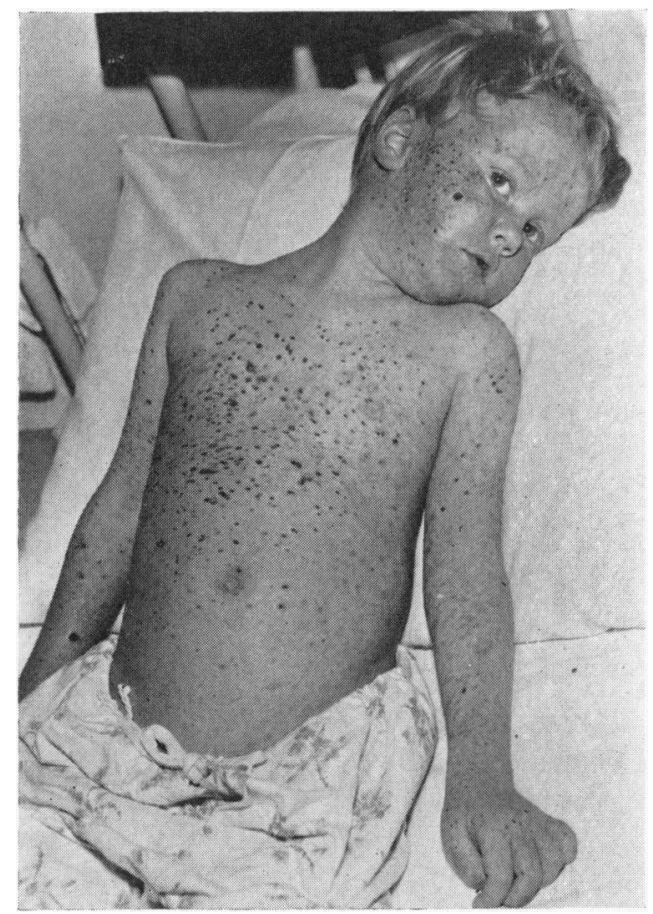

FIG. 3.-Generalized haemorrhagic varicella.

of the trunk, his muscle power had returned to normal. The serum transaminase levels were 23 units (S.G.P.T.) and 49 units (S.G.O.T.) and the creatine phosphokinase 0.4 units. The chest radiograph and the cardiogram were normal.

He was maintained on the régime of prednisolone $5 \mathrm{mg}$. daily and A.C.T.H. 20 units weekly for six months. During this period his muscle power returned to normal. According to his mother he was more active and less easily fatigued than before the onset of his acute illness. It was of particular interest that during these six months, whenever he had an upper respiratory infection, he became generally fatigued, and there was recurrence of his ptosis and difficulty in getting from a supine to a sitting position. These episodes responded to penicillin and temporary increase in the steroid therapy. All therapy was discontinued on August 4, 1963, and he remained well. The S.G.P.T. has remained consistently normal, but his S.G.O.T. rose to 67 units in December, and 87 units in July. On August 21, a week after therapy was stopped, his S.G.O.T. had risen to 98 units and the S.G.P.T. was 50 units. The aldolase was 20 units and the creatine phosphokinase $2 \cdot 3$ units. On September 11 his muscle power was still normal and the S.G.O.T. and S.G.P.T. were 84 and 49 units respectively.

\section{Discussion}

The clinical picture and associated features in this child are in keeping with the diagnosis of an acute dermatomyositis conforming to the subacute variety with an acute exacerbation (Group II of Walton and Adams, 1958).

Unusual features were the respiratory manifestations and abdominal distension. $\mathrm{He}$ had marked respiratory distress, out of proportion to the toxaemia. The miliary shadowing on the radiograph probably reflects pulmonary infiltration due to dermatomyositis. Though pneumonitis is a well-documented feature of various collagen diseases, there are very few cases on record in association with dermatomyositis (Goldfischer and Rubin, 1959). None of the reported cases were children. The fact that the miliary shadowing cleared completely within 10 days of steroid therapy favours this interpretation. Pulmonary oedema as a possible explanation would be unlikely in the absence of any other signs of cardiac failure. The arguments against miliary tuberculosis have already been discussed.

Abdominal distension has been previously recorded in dermatomyositis, and it is thought to be due to involvement of the musculature of the small bowel by the disease process (Pearson, 1962).

From the history it seems likely that this child already had a subacute form of the disease for some time. There are a number of factors that could possibly have precipitated the acute illness. Tuberculosis has been incriminated in previous cases, but appears unlikely in this child, who apparently remained well for four weeks after the enlarged hilar gland was detected and the Heaf test was found to be positive.

The onset of the illness subsequent to the administration of various drugs may be coincidental, and a direct correlation with the administration of the drug is difficult to prove. The sulphonamide cannot be blamed because it was administered 
subsequent to the onset of the acute illness. The PAS may be a responsible factor because there appeared to be some improvement when it was stopped, and an even more striking deterioration when the drug was recommenced.

The value of steroid therapy in dermatomyositis is still disputed (Everett and Curtis, 1957). It is difficult in some reported cases to assess whether death was due to the underlying disease or a complication of steroid therapy. In this patient there was a dramatic response to steroid therapy, but with each minor infection, such as tonsillitis, there was a recurrence of the weakness. This could be well controlled within 24 hours by antibiotics and a temporary increase in the steroids. Another danger of steroid therapy was well demonstrated when the child nearly died of chicken-pox. Because of the dangers of continued steroid therapy, we have considered it desirable to reduce the dose and discontinue the steroids relatively early.

\section{Summary}

A 5-year-old boy presented with clinical and radiological features of miliary tuberculosis, but this diagnosis was disproved and a diagnosis of dermatomyositis established. Complete resolution was achieved on steroid therapy.

We are indebted to the late Dr. Tom Colver, under whose care this patient was admitted, for the opportunity of this study. We also wish to thank Dr. John Lorber for his help and advice and Mr. A. T. Tunstill for the photographs.

\section{REFERENCES}

Everett, M. A. and Curtis, A. C. (1957). Dermatomyositis: A review of nineteen cases in adolescents and children. Arch. intern. Med., 100, 70.

Goldfischer, J. and Rubin, E. H. (1959). Dermatomyositis with pulmonary lesions. Ann. intern. Med., 50, 194.

Pearson, C. M. (1962). Polymyositis. Clinical forms, diagnosis and therapy. Postgrad. Med., 31, 450.

Wagner, E. (1863). Fall einer seltnen Muskelkrankheit. Arch. Heilk., 4, 282.

Walton, J. N. and Adams, R. D. (1958). Polymyositis. Livingstone, Edinburgh and London. 